\title{
OCORRÊNCIA, COMPORTAMENTO E IMPACTOS AMBIENTAIS PROVOCADOS PELA PRESENÇA DE ANTIMICROBIANOS VETERINÁRIOS EM SOLOS
}

\author{
Leandro Alves Pereira, Isabel Cristina Sales Fontes Jardim, Anne Hélène Fostier e Susanne Rath* \\ Departamento de Química Analítica, Instituto de Química, Universidade Estadual de Campinas, CP 6154, 13084-971 Campinas \\ - SP, Brasil
}

Recebido em 1/3/11; aceito em 1/7/11; publicado na web em 20/9/11

\begin{abstract}
OCCURRENCE, BEHAVIOR AND ENVIRONMENTAL IMPACTS CAUSED BY THE PRESENCE OF VETERINARY ANTIMICROBIALS IN SOILS. Antimicrobials, among other veterinary drugs, are used worldwide in industry and agriculture to protect animal health and prevent economic loss. In recent years, they have been detected in various environmental compartments, including soil, surface and groundwater and have become a topic of research interest. Emphasizing this class of compounds, this review presents the different pathways which veterinary drugs enter in the environment, in particular contaminate soils. Also are presented regulatory aspects and guidelines, adsorption/desorption and degradation of these compounds in soils and the consequences of its dispersal in the environment.
\end{abstract}

Keywords: veterinary antimicrobials in soils; adsorption/desorption; environmental impact.

\section{INTRODUÇÃO}

A produção animal em larga escala depende da administração de fármacos veterinários (FV) para a prevenção e o controle de doenças e de parasitas, além da promoção de crescimento das espécies. ${ }^{1,2}$ Deste modo, antimicrobianos, endectocidas, coccidiostáticos, antiprotozoários, antifúngicos, promotores de crescimento, hormônios, anestésicos, tranquilizantes, agentes anti-inflamatórios não esteroidais e produtos para eutanásia são utilizados para assegurar a saúde animal. ${ }^{2,3}$

Ao passo que os antibióticos são exclusivamente produzidos por fungos e bactérias, os antimicrobianos incluem não somente os antibióticos naturais e semissintéticos, mas também todos os compostos que apresentam atividade antibacteriana. As estruturas químicas dos grupos mais importantes de antimicrobianos empregados na medicina veterinária estão apresentadas nas Figuras 1 e 2.

Apesar das taxas de excreção dos antimicrobianos veterinários (AV) dependerem da substância administrada, do modo de aplicação, da espécie animal e do tempo de tratamento, estima-se que em alguns casos até $90 \%$ da dose administrada seja eliminada, em sua forma não metabolizada ou como metabólitos ativos, já que a absorção destas substâncias geralmente ocorre de forma incompleta no organismo. ${ }^{4,5}$

Somado a este fato, encontra-se o elevado consumo de AV registrado mundialmente. Deste modo, grandes quantidades destas substâncias são lançadas no meio ambiente a cada ano, o que faz com que os impactos causados por sua dispersão alcancem grandes proporções, à medida que as águas superficiais e subterrâneas, o ar, solos, plantas, organismos terrestres e aquáticos são ameaçados e a disseminação de bactérias resistentes ocorre no meio ambiente.

Diante destes riscos, o interesse da comunidade científica em questões envolvendo os AV aumentou nas últimas décadas. Atualmente, a disseminação destes fármacos no meio ambiente é tratada, em países desenvolvidos, como uma questão de saúde pública.

Como reflexo desta política, avaliações dos impactos provocados por fármacos a organismos como peixes, algas, micróbios, minhocas, plantas e daphnias passaram a ser requeridos pelo FDA (Food and

*e-mail: raths@iqm.unicamp.br
Drug Administration) em 1980 e pela União Europeia em $1998 .^{6}$ Desde 2006, países europeus proibiram a utilização de AV para a promoção do crescimento de animais produtores de alimentos. ${ }^{7}$ No âmbito internacional os Estados Unidos, Japão e a União Europeia, por meio do Comitê Veterinário Internacional de Harmonização (VICH, Veterinary International Committee on Harmonization), têm se empenhado para padronizar os estudos que avaliam os possíveis riscos provocados por $\mathrm{FV}$ ao meio ambiente e ao homem.

Com o destaque dado aos antimicrobianos, este trabalho apresenta uma revisão de artigos recentes para a discussão dos seguintes temas: as formas de introdução dos FV no meio ambiente, os aspectos regulatórios envolvendo o emprego destas substâncias, a sorção/dessorção e degradação das mesmas no solo e os impactos provocados pela dispersão destes contaminantes no ambiente.

\section{CONSUMO E INTRODUÇÃO DE ANTIMICROBIANOS VETERINÁRIOS NO MEIO AMBIENTE}

A falta de informações atualizadas a respeito da produção, venda e do consumo de FV ainda é comum em quase todos os países. ${ }^{3,8}$ Kools et al. ${ }^{9}$ estimaram o consumo de aproximadamente 5 mil toneladas de AV em países europeus no ano de 2004. Em 2009, a venda de antimicrobianos na Europa movimentou mais de 1 bilhão de dólares. ${ }^{10}$ Neste mesmo período, a comercialização de AV no Brasil atingiu a quantia de 379 milhões de dólares. ${ }^{11}$ Nos Estados Unidos estima-se que o consumo de AV seja de aproximadamente 10 mil toneladas por ano. ${ }^{12}$

Conforme mostra a Figura 3, a introdução de antimicrobianos e outros fármacos no ambiente pode ocorrer pela contaminação por efluentes industriais e domésticos, pelas más condições de armazenagem dos produtos não utilizados ou com prazo de validade expirado, através de tratamentos administrados na aquicultura e por meio dos excrementos dos animais. Dentre estes, as fezes e a urina são as maiores fontes de contaminação, já que o esterco é muitas vezes lançado diretamente no pasto ou empregado como fertilizante em terras cultiváveis sem nenhum cuidado prévio.

Uma vez que os processos atuais de tratamento dos esgotos não são capazes de eliminar completamente os antimicrobianos, a aplicação de biossólidos, provenientes do processo de tratamento de 


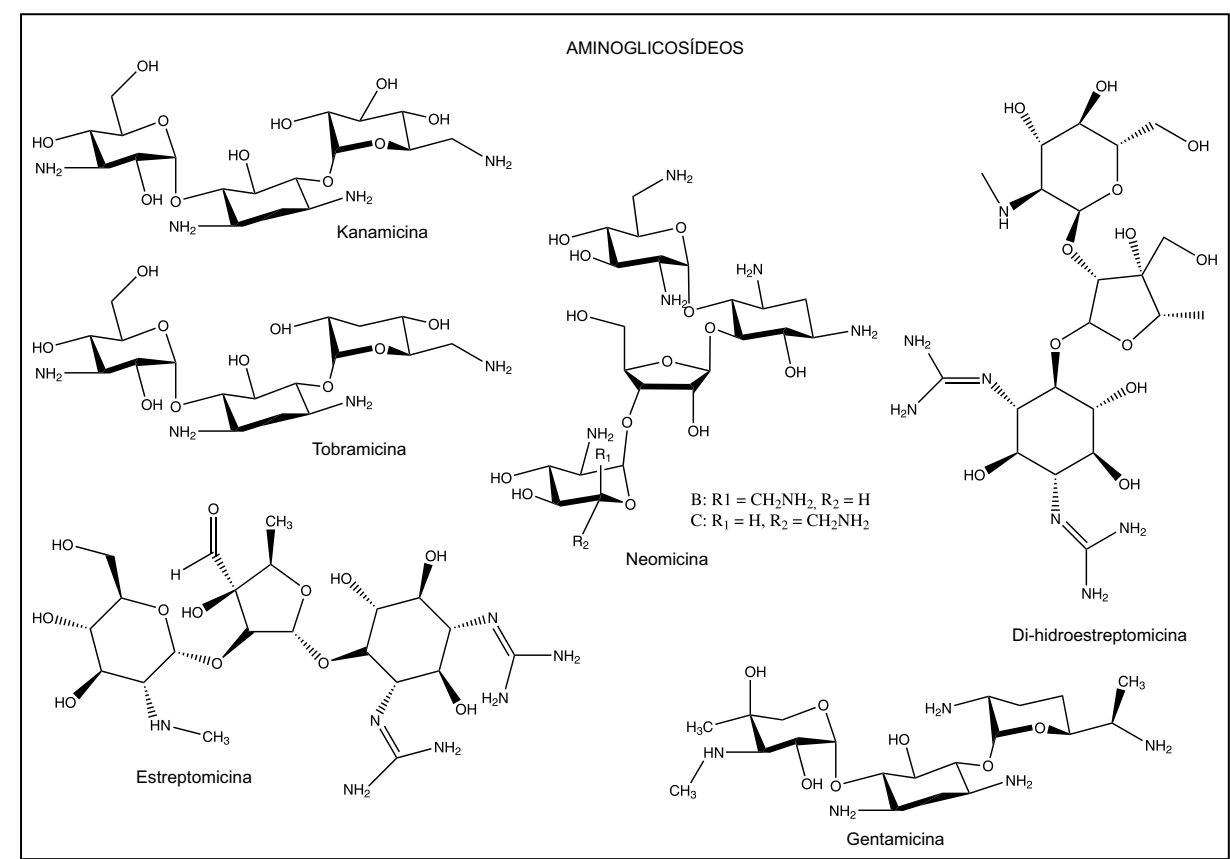

Cloranfenicol




Figura 1. Estruturas químicas dos principais antimicrobianos naturais 

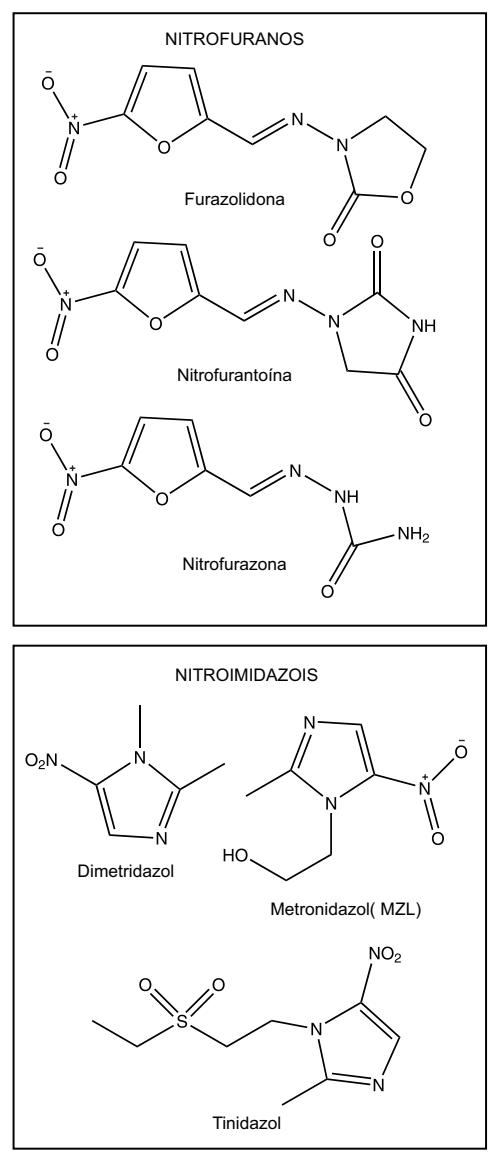

QUINOLONAS/FLUOROQUINOLONAS (FQ)<smiles>CCn1cc(C(=O)O)c(=O)c2cc3c(cc21)OCO3</smiles>

<smiles>CN1C[C@@H]2C[C@H]1CN2c1cc2c(cc1F)C(=O)CCN2C1CC1</smiles><smiles>O=c1ccn(C2CC2)c2cc(N3CCNCC3)c(F)cc12</smiles><smiles>CC1CCc2cc(F)cc3c(=O)c(C(=O)O)cn1c23</smiles><smiles>C[C@@H]1COc2c(N3CCN(C)CC3)c(F)cc3c(=O)c(C(=O)O)cn1c23</smiles><smiles>CCn1cc(C(=O)O)c(=O)c2ccc(C)nc21</smiles><smiles>COc1ccc(NS(=O)(=O)c2ccc(N)cc2)nn1</smiles>

Figura 2. Estruturas químicas dos principais antimicrobianos sintéticos

esgotos urbanos, pode se tornar uma ameaça ao meio ambiente já que fármacos de uso humano e seus metabólitos podem ser lixiviados no solo e atingir ecossistemas terrestres ou aquáticos. . $^{3,13-15}$

O uso controlado de fertilizantes naturais certamente é benéfico, uma vez que contribui para a reciclagem da matéria orgânica e dos nutrientes no solo. Nos Estados Unidos estima-se que a cada ano 132 milhões de toneladas de estrume, produzido por bovinos, suínos e aves, sejam utilizadas como fertilizantes em uma área de 9 milhões de hectares. ${ }^{16}$ Entretanto, para que esta prática seja segura os riscos de contaminação devem ser minimizados através da degradação parcial ou total dos resíduos de AV. No entanto, muitas vezes o esterco é coletado, armazenado e espalhado pelo solo sem nenhum tratamento prévio, o que pode vir a prejudicar o meio ambiente. ${ }^{1}$

Alguns estudos realizados in situ demonstraram a permanência de AV em solos, provocada por esta prática. Christian et al. ${ }^{17}$ detec- taram sulfadimidina, em concentração de $15 \mu \mathrm{g} \mathrm{kg}^{-1}, 7$ meses após a aplicação de esterco líquido de gado e suínos em solos. Hamscher $e t$ al. ${ }^{18}$ evidenciaram a presença de tetraciclina (TC) e oxitetraciclina (OTC) a uma profundidade de $30 \mathrm{~cm}$, até 7 meses após a fertilização de solos com esterco líquido de suínos. Stoob et al. ${ }^{19}$ confirmaram a presença de sulfadiazina (SFZ) e sulfatiazol, $15 \%$ em relação à concentração inicial, 3 meses após a aplicação de esterco suíno em solos. AGA et al. ${ }^{20}$ detectaram OTC, anidro-OTC e anidro-TC 144 dias após a fertilização de solo com esterco de gado.

\section{IMPACTOS PROVOCADOS PELA PRESENÇA DE ANTIMICROBIANOS VETERINÁRIOS NO SOLO}

Apesar dos solos serem habitados por micro-organismos que naturalmente produzem antimicrobianos, a concentração destes compostos 
Fármacos de consumo humano

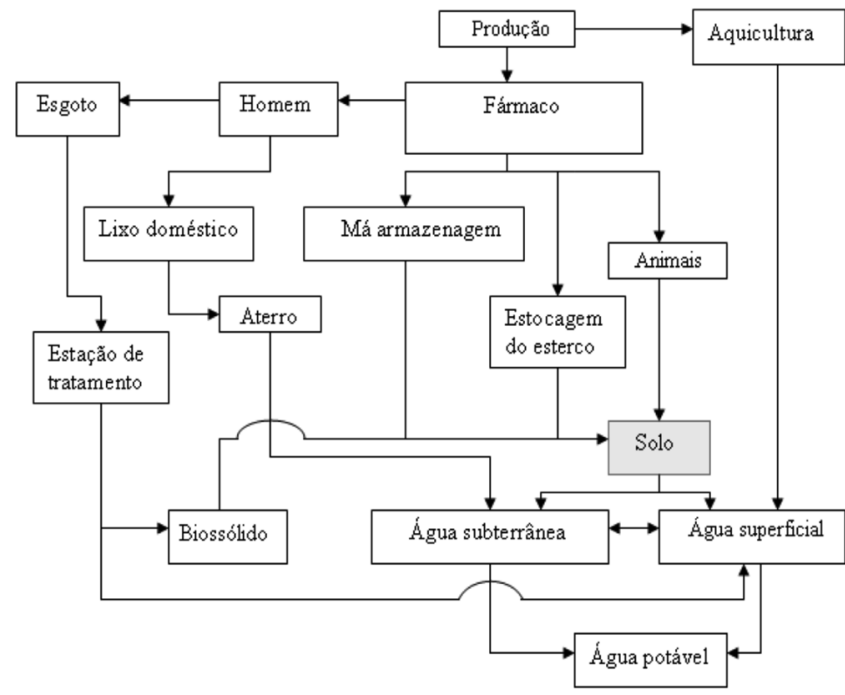

Figura 3. Principais rotas de contaminação do solo por fármacos de uso humano e veterinário

no meio ambiente tem aumentado. ${ }^{21}$ Embora estas concentrações sejam relativamente baixas, pouco se sabe a respeito dos efeitos provocados em longo prazo, pela exposição a estes níveis de contaminação. ${ }^{3}$

Tal situação é agravada pelo fato de que a sorção ou fixação destes fármacos no solo nem sempre acompanha a eliminação de sua atividade antimicrobiana. ${ }^{15,21} \mathrm{Em}$ solos nos quais a TC e a tilosina (TIL) foram sorvidas verificou-se, respectivamente, decréscimos de 46 e $29 \%$ no desenvolvimento das unidades formadoras de colônias de Salmonella sp. e Escherichia coli. ${ }^{22}$ Inibições de 21/19,6 e 37,5/25,8\% foram observadas no crescimento das espécies Trichorderma koningii Oudem e Fusarium moniliforme Sheldon em solos contaminados por ciprofloxacina (CIP) e enrofloxacina (ENR), respectivamente. ${ }^{23}$

A bioacumulação de antimicrobianos em plantas e organismos pequenos é um dos impactos provocados pela dispersão destes compostos no solo. Kinney et al. ${ }^{24}$ observaram a bioacumulação de trimetoprima (TMP) e diversos compostos orgânicos em minhocas, após a aplicação de esterco e de lodo de esgoto ao solo. Boxall et $a l .{ }^{25}$ detectaram florfenicol (FLO) e TMP em alface, além de ENR, FLO e TMP nas raízes da cenoura, ambas cultivadas em solos contaminados com os fármacos. A sulfametazina (SMT) foi detectada, em concentrações variando entre 0,1 a $1,2 \mathrm{mg} \mathrm{kg}^{-1}$, em tecidos de milho, alface e batata. ${ }^{16}$ Clortetraciclina (CTC), entre 2 a $17 \mathrm{ng} \mathrm{g}^{-1}$, foi encontrada no repolho, milho e cebola verde também cultivados em solos fertilizados com esterco contaminado. ${ }^{26}$

Mesmo não havendo evidências de que a bioacumulação de antimicrobianos em plantas ofereça riscos à saúde humana, há estudos que mostraram que o crescimento de espécies vegetais foi prejudicado por alguns fármacos. Empregando concentrações elevadas de sulfadimetoxina (SDX) no solo, Migliori et al. ${ }^{27,28}$ confirmaram a inibição do desenvolvimento pós-germinativo de várias plantas. Hordeum disthicum e Zea mays apresentaram peso inferior em relação às plantas cultivadas em solos não contaminados. O tamanho das raízes, cotilédones e da folhagem da Amaranthus retroflexus, Plantago major e Rumex acetosella foi menor quando comparado às amostras de controle. Jjemba ${ }^{29}$ constatou que o metronidazol (MZL), em concentrações menores que $0,5 \mathrm{mg} \mathrm{g}^{-1}$ de solo, afetou severamente o crescimento da soja.

Além dos prejuízos causados às espécies vegetais, outros danos também podem ser provocados, já que muitos micro-organismos do solo são sensíveis aos antimicrobianos. Estima-se que, respectivamente, $10^{6}$ e $10^{9}$ bactérias por grama, presentes em solos cultiváveis e florestais, sejam responsáveis pela imobilização de minerais e processos naturais de decomposição. Com a morte destes microorganismos a capacidade do solo em degradar outros contaminantes, como os agrotóxicos, seria prejudicada. ${ }^{2,4}$

Outra preocupação em relação aos AV é o desenvolvimento de bactérias resistentes, provocado por seleção natural, troca de material genético entre bactérias do solo e aquelas presentes nas fezes de animais ou entre bactérias produtoras de antimicrobianos..$^{22,30}$

Esta preocupação fez com que a União Europeia proibisse o emprego de $\mathrm{AV}$, com a finalidade de promover o crescimento em animais produtores de alimento, já que existe o receio de que bactérias resistentes possam infectar o homem por meio do consumo destes produtos. Outra ação tomada, pelo FDA e o VICH, foi a elaboração de guias normativas que orientam a avaliação de novos AV no que diz respeito ao seu potencial em promover o desenvolvimento de bactérias resistentes. ${ }^{31,32}$

Atualmente, genes cada vez mais resistentes têm sido isolados a partir de bactérias de origem ambiental e animal.,22 Bactérias Gram-negativas com $\beta$-lactamase de espectro estendido resistentes às penicilinas e bactérias multirresistentes a pneumococos têm sido isoladas em hospitais. ${ }^{33}$ Pseudomonas spp. e Bacillus cereus resistentes a antimicrobianos foram isolados após a aplicação de esterco de suínos ao solo. ${ }^{34}$ Bactérias resistentes à TIL desenvolveram-se em solos fertilizados com esterco de bovinos, suínos e frangos tratados com doses subterapêuticas do antimicrobiano. ${ }^{35}$ Sengel $\varnothing \mathrm{v}$ et al..$^{30}$ encontraram um número elevado de bactérias resistentes à TC após a aplicação de esterco de suínos ao solo. Contudo, o número destes organismos diminuiu gradativamente e atingiu níveis equivalentes àqueles encontrados no solo de controle após 5 meses. Para o conhecimento de outros estudos e melhor entendimento das consequências provocadas pela dispersão de estercos contaminados no solo pode ser consultado o trabalho de Venglovsky et al. ${ }^{36}$

Foi comprovado que até mesmo fármacos com alta capacidade de sorção no solo, tais como as fluoroquinolonas (FQ) e tetraciclinas (TET), não permanecem imóveis, uma vez que têm sido encontrados em ambientes aquáticos de áreas urbanas e rurais. ${ }^{37-39}$ Desta forma, fica claro que não só os organismos terrestres sofrem com a dispersão de AV no meio ambiente, já que ecossistemas aquáticos também podem ser afetados.

Ácido nalidíxico, eritromicina, TIL, NOR, CTC, doxiciclina (DC), demeclociclina, TC, CIP, ENR, lincomicina, SDX, sulfamerazina, sulfacloropiridazina (SFP), SMT, sulfametoxazol (SMZ), acetilsulfametoxazol e TMP já foram encontrados em águas de rios e córregos. ${ }^{40-48}$ TIL foi encontrada em águas potáveis e o SMZ em águas subterrâneas. ${ }^{42,49}$

\section{ASPECTOS REGULATÓRIOS ENVOLVENDO O USO DE FÁRMACOS VETERINÁRIOS}

Considerando que a exposição a resíduos de FV pode vir a ser prejudicial à saúde humana, a Comissão do Codex Alimentarius vem estabelecendo uma série de limites máximos de resíduos (MRL, Maximum Residue Limit) para alimentos. Esses MRL são estabelecidos por meio de avaliações toxicológicas e segundo recomendações do Comitê de Peritos em Aditivos Alimentares (JECFA, Joint Expert Committee on Food Additives) da Organização das Nações Unidas para a Agricultura e a Alimentação e da Organização Mundial da Saúde. ${ }^{50}$

Apesar de haver recomendações para alimentos, até os dias atuais não existem legislações que estabeleçam limites específicos para a concentração de FV no solo. Somente em 2001 a Agência Europeia para a Avaliação de Produtos Medicinais (EMEA, European Agency for the Evaluation of Medical Products) determinou um limite genérico de $100 \mu \mathrm{g} \mathrm{kg}^{-1}$ para $\mathrm{FV}$ em solo. Este valor foi estabelecido com 
Tabela 1. Dados referentes à sorção e dessorção de antimicrobianos em solos

\begin{tabular}{|c|c|c|c|c|c|c|c|c|}
\hline Antimicrobiano & Solo/matriz & $p H$ & $\% \mathrm{CO}^{*} / \mathrm{MO}^{* *}$ & $K_{d}\left(\mathrm{~L} \mathrm{~g} \mathrm{~g}^{-1}\right)$ & $K_{o c}\left(\mathrm{~L} \mathrm{~g}^{-1}\right)$ & $K_{F}^{a d s 1}$ & $K_{\text {des }}\left(\mathrm{L} \mathrm{g} \mathrm{g}^{-1}\right)$ & Ref. \\
\hline$\left[{ }^{14} \mathrm{C}\right]$ Efrotomicina & $\mathrm{SC}$ & $5,0 / 6,7 / 7,5$ & $0,1-4,6^{* *}$ & $(8-290) 10^{-3}$ & $1,5-11$ & $(8-336) 10^{-3}$ & $(14-480) 10^{-3}$ & 59 \\
\hline Carbazepina & SC, solo fertilizado & $7,0 / 7,6$ & $2,5 / 2,7 * *$ & $13 / 20$ & $885 / 1250$ & - & $20-48$ & 60 \\
\hline Ciprofloxacina & $\mathrm{SC}$ & $4 / 7$ & $0,05-8,9 *$ & $150-45000$ & - & - & - & 61 \\
\hline Clortetraciclina & FAR, HS, FAR-SH & $5,8 / 7,0$ & $<5,2 *$ & $1 \times 10^{4}-\infty$ & - & - & $7,5 \times 10^{3}-\infty$ & 57 \\
\hline Enrofloxacina & $\mathrm{SC}, \mathrm{FAG}$ & $4,8-6,6$ & $0,7-1,6^{*}$ & $140-5612$ & $(1,7-7,7) 10^{4}$ & - & $687-27504$ & 62 \\
\hline Metronidazol & ARE, ARB, ARN & $5,6-6,3$ & $1,1-1,6^{*}$ & $0,54-0,67$ & $39-56$ & $0,74-0,80$ & - & 63 \\
\hline Norfloxacina & $\mathrm{SC}, \mathrm{SMO}$ & $4 / 7 / 10$ & $1,9-3,3 * *$ & $\approx 0,1-0,6$ & $5-30$ & 1189-1833 & - & 64 \\
\hline Ofloxacina & $\mathrm{SC}$ & $4,3 / 6,8$ & $0,4 / 7,1^{*}$ & $(1,2-3,6) 10^{3}$ & $(50-322) 10^{3}$ & $(0,8-3,2) 10^{3}$ & $(4,0-4,5) 10^{3}$ & 55 \\
\hline Olaquindox & ARE, ARB, ARN & $5,6-6,3$ & $1,1-1,6^{*}$ & $0,69-1,67$ & $46-116$ & $0,84-1,20$ & - & 63 \\
\hline \multirow[t]{3}{*}{ Oxitetraciclina } & ARE, ARB, ARN & $5,6-6,3$ & $1,1-1,6^{*}$ & $417-1026$ & $(2,8-9,3) 10^{4}$ & - & $111-116$ & 63 \\
\hline & Montimorilonita & $1,5-11$ & - & - & - & $295-676$ & - & 65 \\
\hline & Óxido de ferro & $4-9$ & $0,12 / 0,23^{*}$ & $80-289$ & - & - & - & 66 \\
\hline \multirow[t]{2}{*}{ Sulfacloropiridazina } & ARE, ARL & $6,5 / 6,8$ & - & $0,9 / 1,8$ & - & - & - & 59 \\
\hline & SLT, ARN & $7,2 / 7,5$ & $0,94 / 1,8 *$ & - & - & $3,1-6,4$ & - & 67 \\
\hline Sulfadiazina & ST, FAR, FAG & $6,7-7,0$ & $1,6-4,4^{*}$ & $1,4-2,8$ & $37-125$ & $<6,5$ & - & 68 \\
\hline Sulfadimetoxina & ST, FAR, FAG & $6,7-7,0$ & $1,6-4,4^{*}$ & $2,3-4,6$ & $89-144$ & $<6,5$ & - & 68 \\
\hline Sulfadimidina & ST, FAR, FAG & $6,7-7,0$ & $1,6-4,4^{*}$ & $2,4-2,7$ & $61-150$ & $<6,5$ & - & 68 \\
\hline Sulfametazina & SLT, ARN & $7,2 / 7,5$ & $0,94 / 1,8^{*}$ & - & - & $4,0-6,8$ & - & 67 \\
\hline Sulfametoxazol & $\mathrm{SC}$ & $4,3 / 6,8$ & $0,4 / 7,1^{*}$ & $0,23-38$ & $62-530$ & $0,28-36$ & $0,40-43$ & 55 \\
\hline Sulfanilamida & ST, FAR, FAG & $6,7-7,0$ & $1,6-4,4 *$ & $1,5-1,7$ & $34-106$ & $<6,5$ & - & 68 \\
\hline \multirow[t]{2}{*}{ Sulfapiridina } & SLT & $6,9-7,0$ & $1,6-2,4^{*}$ & $1,6-7,4$ & $101-308$ & $2,2-5,5$ & - & 69 \\
\hline & ST, FAR, FAG & $6,7-7,0$ & $1,6-4,4^{*}$ & $3,1-3,5$ & $80-218$ & $<6,5$ & - & 68 \\
\hline Tetraciclina & FAR, SH, AR-SH & $5,8 / 7,0$ & $3,2 / 5,2 *$ & $4 \times 10^{3}-\infty$ & - & - & $1,4 \times 10^{4}-\infty$ & 57 \\
\hline Tilosina & ARE, ARB, ARN & $5,6-6,3$ & $1,1-1,6^{*}$ & $8,3-128$ & $553-7988$ & $2,3-7,0$ & $7,6-18,9$ & 63 \\
\hline
\end{tabular}

$1-K_{F}^{a d s}$ se iguala a $K_{d}$ somente se $n=1$. ARE: barro-arenoso, ARB: areia-barrenta, ARL: barro-argiloso, ARN: arenoso, CO: carbono orgânico (*), FAG: fração argilosa, FAR: fração arenosa, SH: substâncias húmicas, AR-SH: complexo argila-substâncias húmicas, SC: solo completo, SLT: solo siltoso, SMO: solo sem matéria orgânica, MO: matéria orgânica (**).

base em estudos toxicológicos realizados com os FV autorizados nos Estados Unidos e está abaixo dos níveis prejudiciais observados em minhocas, micróbios e plantas. ${ }^{51}$

Segundo estabelecido pela EMEA, a avaliação dos impactos causados por FV no ambiente deve ser realizada em duas fases, conforme esquematizado na Figura 4.

A fase I consiste em três ações: 1) cálculo da concentração ambiental previsível (PEC, predicted environmental concentration) do FV e/ou metabólitos que são lançados no solo por meio das fezes e urina dos animais; 2) cálculo do quociente de risco (RQ, risk quocient) e, 3) realização de estudos físico-químicos, ambientais e toxicológicos. ${ }^{52}$

Para que a PEC seja determinada utilizam-se equações que levam diversos parâmetros em consideração, como o número de animais criados no espaço por ano, o tipo de criação, a dose diária do fármaco, os dias de tratamento, o peso corpóreo do animal, a densidade do solo, entre outros. A partir da PEC o valor de RQ pode ser calculado a partir da Equação 1:53

$$
R Q=\frac{P E C}{P N E C}
$$

onde: PNEC (predicted no effect concentration) é a concentração previsível sem efeito.

Se RQ for menor que 1 nenhuma ação precisa ser tomada, pois considera-se que o $\mathrm{FV}$ e/ou seus metabólitos não ofereçam riscos significativos ao meio ambiente. Por outro lado, se RQ for maior que 1 ou se o fármaco for altamente persistente, a PEC precisa ser recalculada para que seu valor seja refinado. Para tanto, informações a respeito do metabolismo e da excreção do fármaco, além de sua biodegradação no esterco, no solo e em ambientes aquáticos devem

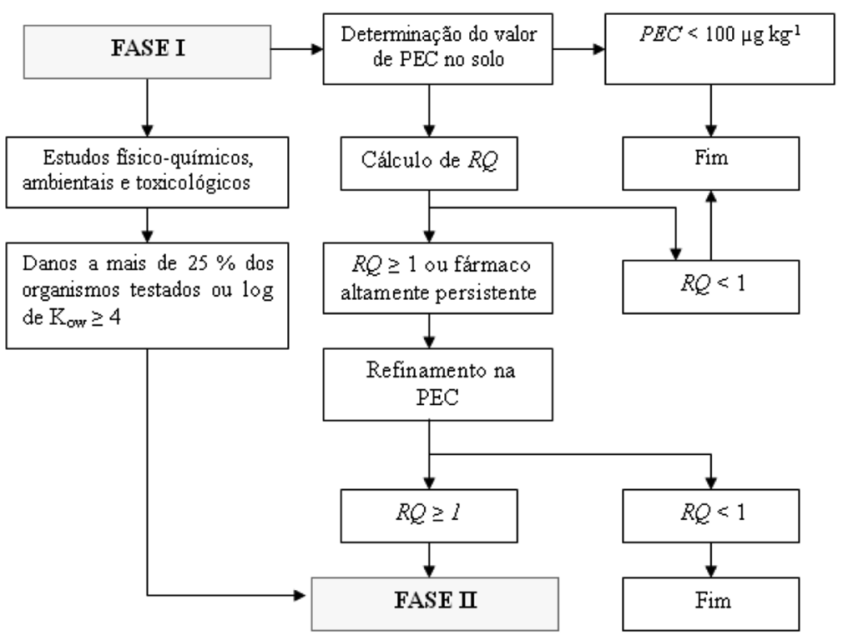

Figura 4. Esquema proposto pela VICH para a avaliação dos riscos ambientais provocados por fármacos veterinários. PEC: concentração ambiental previsível, $R Q$ : quociente de risco, $K_{o w}$ : coeficiente de partição octanol-água. Adaptado da ref. 52

ser consideradas. A partir do refinamento da PEC, um novo valor de RQ é então determinado. Se este valor for inferior a 1 a avaliação termina. Do contrário, a fase II deve ser realizada. ${ }^{52}$

$\mathrm{Na}$ fase I também é feito o levantamento de dados físicoquímicos, farmacológicos-toxicológicos e toxicocinéticos, além de informações sobre a degradabilidade e a persistência do FV e seus metabólitos no ambiente. Conforme estabelecido pela EMEA, as seguintes avaliações devem ser feitas: ${ }^{52}$ estudos das propriedades físico-químicas do FV: solubilidade na água, constantes de 
dissociação na água, espectro de absorção UV-VIS, coeficiente de partição octanol-água, pressão de vapor e ponto de fusão; estudos ambientais - sorção e dessorção do FV no solo, fotólise, hidrólise, biodegradação no solo e degradação em sistemas aquáticos. Sendo que estes dois últimos devem ser realizados no solo ou na água, dependendo de em qual meio o FV é preferencialmente acumulado; estudos dos efeitos provocados pelo FV a organismos terrestres (plantas, minhocas, larvas da mosca e do besouro do esterco) ou aquáticos (algas, daphnia, peixes e crustáceos), dependendo de qual ambiente será mais atingido.

Se nesta última etapa forem verificados efeitos prejudiciais a mais de $25 \%$ dos micro-organismos do solo ou se o log de $\mathrm{K}_{\text {ow }}$ (coeficiente de partição octanol-água) calculado para o FV for maior ou igual a 4, a EMEA estabelece que a fase II seja realizada.

A fase II também consiste em avaliações dos efeitos provocados pelos FV a organismos terrestres e aquáticos. Contudo, novas espécies devem ser estudadas e deve ser calculada a concentração de efeito não observado (NOEC, no-observed effect concentraction) nos organismos avaliados. Além disto, recomenda-se que fatores de bioconcentração (BCF, bioconcentration factors) sejam calculados por meio da relação quantitativa estrutura atividade (QSAR, quantitative structure activity relationship) e que o valor de RQ seja novamente determinado. ${ }^{52}$

Se RQ for novamente maior que 1 , ou se os BCF $\geq 1000$, um laudo de avaliação dos impactos ambientais deve ser entregue às autoridades competentes, a fim de que a comercialização do novo FV seja autorizada. ${ }^{52}$

\section{SORÇÃO DE ANTIMICROBIANOS VETERINÁRIOS EM SOLOS}

Devido à presença de grupos polifenólicos e carboxílicos ionizáveis nas substâncias húmicas $(\mathrm{SH})$ e aos hidróxidos metálicos, que possuem carga negativa ou positiva de acordo com o $\mathrm{pH}$ em que se encontram, o solo funciona como sítio de sorção de diversos compostos, dentre estes, os $\mathrm{AV} .{ }^{54}$ Para tanto, vários mecanismos podem estar envolvidos: adsorção à superfície de constituintes minerais, troca iônica, sorção à matéria orgânica, formação de complexos com íons metálicos $\left(\mathrm{Ca}^{2+}, \mathrm{Mg}^{2+}, \mathrm{Fe}^{3+}\right.$ ou $\left.\mathrm{Al}^{3+}\right)$ e ligação de hidrogênio entre grupos polares dos $\mathrm{AV}$ e os ácidos húmicos do solo. ${ }^{1}$

A sorção de AV no solo é um processo complexo, sendo influenciado pela combinação entre fatores ambientais e as características dos fármacos. Sendo assim, depende do conteúdo de matéria orgânica do solo, de sua quantidade de argila, de sua capacidade de troca iônica e de seu $\mathrm{pH} .{ }^{55}$ Além destes, outros fatores como a fotoestabilidade do fármaco, sua taxa de degradação, sua capacidade de lixiviação pela água e suas propriedades físico-químicas também estão envolvidos. ${ }^{1}$

Há alguns estudos que evidenciam a relação de dependência entre a sorção de antimicrobianos com as características do solo e do fármaco em si. Sassman e Lee ${ }^{56}$ utilizaram 8 solos distintos (em relação ao $\mathrm{pH}, \%$ de carbono orgânico, \% de argila e capacidade de troca catiônica e aniônica) verificando que a sorção da TC, OTC e CTC se modificou consideravelmente, principalmente em função do $\mathrm{pH}$ e da capacidade de troca catiônica dos solos avaliados. Pils e Laird $^{57}$ estudaram a sorção de TC e CTC em componentes de 2 solos distintos. Isolando as SH do restante do solo foi possível constatar a sorção preferencial dos dois fármacos na fração argilosa, seguida pelas $\mathrm{SH}$ e, por último, pela mistura argila-SH. Boxall et al. ${ }^{58}$ variaram o $\mathrm{pH}$ do solo argiloso e arenoso verificando o comportamento $\mathrm{pH}$ dependente da SFP. Neste caso, a sorção do composto tornou-se menor, em ambos os solos, em função do aumento do pH. Outros estudos de sorção de antimicrobianos em solos são apresentados na Tabela 1.

Apesar de resultados experimentais indicarem o acréscimo na sorção de fármacos como consequência do aumento na porcentagem de matéria orgânica (MO) do solo, ${ }^{55,69}$ há estudos que contradizem estas observações. Jie et al ${ }^{64}$ compararam a sorção de NOR em três solos com e sem MO. Neste caso, foi verificado que a capacidade de sorção da NOR foi maior nos solos sem MO. Resultados semelhantes também foram obtidos no caso da TC e CTC. ${ }^{57}$ A explicação para o fenômeno pode estar no fato de solos sem MO apresentarem mais sítios de sorção, ao passo que a MO poderia mascarar estes sítios e bloquear o acesso dos fármacos aos mesmos. ${ }^{57,64}$ Apesar desta hipótese, a influência do conteúdo de carbono orgânico no valor do coeficiente de distribuição de adsorção $\left(K_{d}\right)$ de antimicrobianos em solos ainda não foi esclarecida. ${ }^{61}$

Parâmetros como o $K_{d}$, o coeficiente de adsorção normalizado pelo carbono orgânico $\left(K_{o c}\right)$, o $p K a$ e a solubilidade também são empregados para estimar o grau de sorção de AV em solos. Para a verificação destes dados algumas referências podem ser consultadas. ${ }^{3,15,21,70}$

$\mathrm{O} K_{d}$ é definido como a razão entre a concentração do fármaco (ou qualquer outra substância química) adsorvida na matriz sólida (neste caso, solo ou sedimento) e aquela que permanece em equilíbrio na fase aquosa. ${ }^{15}$ Uma vez que $K_{d}$ é difícil de ser comparado, em razão da variação das múltiplas condições de cada ambiente, sua substituição por $K_{o c}$ (calculado como a razão entre $K_{d}$ e a \% de carbono orgânico do solo) é algumas vezes empregada, ${ }^{13}$ apesar do uso universal deste parâmetro em estudos de sorção de antimicrobianos em solos ainda estar em discussão. ${ }^{3,55}$

Valores altos de $K_{d}$ para FQ e TET indicam a grande tendência à sorção destes fármacos em solos e sedimentos, já que estes compostos são passíveis de interação com sítios negativos e positivos do solo devido à presença de diversos grupos ionizáveis e à capacidade de formação de espécies catiônicas, aniônicas ou zwiteriônicas. ${ }^{37,38,64,71}$ No caso das TET, o grupo amônio quaternário, quando positivamente carregado, pode interagir com sítios aniônicos via troca catiônica. Já, o grupo tricarbonil metano ceto-enol, quando negativamente carregado, pode interagir com sítios positivos do solo via ponte catiônica. ${ }^{57}$

Em decorrência de baixos valores de $K_{d}$ e da formação de interações mais fracas com o solo (como interações de van der Waals e ligações de hidrogênio), fármacos como as sulfonamidas (SF) apresentam alta mobilidade no meio ambiente. ${ }^{15,19,68,72}$ Deste modo, estes compostos podem ser facilmente lixiviados alcançando águas superficiais e lençóis freáticos e, consequentemente, contaminar a água potável. ${ }^{13,25}$

Até o presente momento, poucos trabalhos foram realizados com o intuito de elucidar os mecanismos envolvidos na sorção de antimicrobianos em solos. Utilizando um modelo empírico Figueroa et $a l .{ }^{73}$ consideraram a sorção total da OTC como a soma da sorção das formas catiônica $\left(K_{d}^{\text {OTC+}}\right)$ e zwitteriônica $\left(K_{d}^{\text {OTC0})}\right.$ do fármaco. Segundo os autores, a dependência de $K_{d}^{\text {OTC+ }}$ com a força iônica do meio indicou a troca iônica como o mecanismo mais importante para a sorção da OTC na sua forma catiônica. Concomitantemente, a

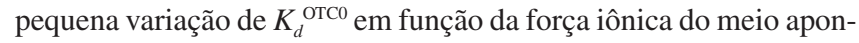
tou o processo de complexação como dominante para a sorção das espécies zwitteriônicas de OTC. Este mesmo pesquisador empregou um programa computacional para determinar os $K_{d}$ de reações entre a OTC e a hematita em diferentes valores de $\mathrm{pH}$. Como resultado, verificou-se que as espécies aniônicas do fármaco apresentaram tendência superior, em relação às formas zwitteriônicas, à complexação com a superfície neutra do óxido. ${ }^{66}$ Em contrapartida, no modelo de sorção desenvolvido por Sassman e Lee, ${ }^{56}$ os $K_{d}$ calculados para a TC, OTC e CTC foram maiores para as espécies catiônicas, considerando a sorção dos fármacos nos sítios negativos do solo.

Diferentes mecanismos de interação entre antimicrobianos e solos foram constatados por outros autores. Através das técnicas de 
difração de raios-X e infravermelho por transformada de Fourier foi possível identificar mecanismos de ligação multifuncional de hidrogênio, interação hidrofóbica, ponte catiônica, transferência de carga $\pi-\pi$ e difusão de TET entre as intercamadas de argilas. ${ }^{57,65}$ No caso da ENR, foi constatada a sorção via ponte catiônica a cátions divalentes e monovalentes entre intercamadas de montimorilonita. ${ }^{62}$ Em estudos de sorção da CIP foram identificados mecanismos de troca catiônica, ponte catiônica e complexação em 23 solos. ${ }^{61}$

\section{Determinação dos coeficientes de sorção e dessorção de contaminantes em solos}

A mobilidade dos AV e outros contaminantes em solos pode ser avaliada por meio de estudos de adsorção/dessorção e de lixiviação, os quais, de acordo com a EMEA, devem ser realizados segundo as orientações da OECD 106 e OECD 312, respectivamente. ${ }^{74,75}$

De acordo com a OECD 106, o coeficiente de sorção de contaminantes é determinado por meio da adição de uma alíquota com volume e concentração conhecidas do composto de interesse às amostras de solos inicialmente secas, pesadas e pré-equilibradas com $\mathrm{CaCl}_{2} 0,01 \mathrm{~mol} \mathrm{~L}^{-1}$. As misturas devem ser agitadas até que seja atingido o equilíbrio entre as fases. A seguir, o sobrenadante deve ser separado por centrifugação, filtrado e analisado. A concentração da substância adsorvida no solo $\left(C_{s}^{a d s}\right)$ é, então, calculada como a diferença entre sua concentração inicial e a concentração em equilíbrio na fase aquosa $C_{a q}^{a d s} \cdot{ }^{74}$

A OECD 106 recomenda que $C_{s}^{a d s}$ seja plotada em função de $C_{a q}^{a d s}$ e que a isoterma obtida seja ajustada à Equação de adsorção de Freundlich (Equação 2a, 2b) para o cálculo do coeficiente de adsorção de Freundlich $\left(K_{F}^{a d s}\right)$ e de $K_{o c}$.

$$
C_{s}^{a d s}=K_{F}^{a d s} \cdot C_{a q}^{a d s} 1 / n
$$

ou na forma linear:

$$
\log C_{s}^{a d s}=\log K_{F}^{a d s}+1 / n \cdot \log C_{a q}^{a d s}
$$

onde: $n$ é a constante de regressão.

$\mathrm{O}$ ajuste ao modelo de Freundlich foi satisfatoriamente obtido em diversos estudos de sorção de antimicrobianos em solos, ${ }^{56,58,65,67,68}$ apresentando melhor coeficiente de correlação $(r)$ quando comparado ao modelo de sorção de Langmuir. ${ }^{64,69}$ Entretanto, em outras situações, o modelo de Langmuir (Equação 3) mostrou-se mais adequado. ${ }^{61,66,76}$ Para o melhor entendimento destes modelos pode ser consultado o trabalho publicado por Travis e Etnier. ${ }^{77}$

$$
C_{s}^{a d s}=\frac{C_{s, \max x}^{a d s} K_{L} C_{a q}^{a d s}}{1+K_{L} C_{a q}^{a d s}}
$$

onde: $K_{L}$ e $C_{s, m a ́ x}^{a d s}$ são o coeficiente de sorção de Langmuir e a capacidade máxima de sorção do sorbente, respectivamente.

Os estudos de dessorção são realizados com o objetivo de investigar se a retenção do contaminante no solo ocorre de forma reversível ou não. Tal informação é de grande importância, pois permite verificar a mobilidade do composto e prever se o mesmo pode ser lixiviado e carregado para mananciais de água. ${ }^{74}$

De acordo com a OECD 106, o estudo é inicialmente realizado tal como no experimento de adsorção. Contudo, após o estabelecimento do equilíbrio entre a fase aquosa e o solo, o sobrenadante é retirado e o volume da solução é reposto com $\mathrm{CaCl}_{2} 0,01 \mathrm{~mol} \mathrm{~L}^{-1}$ (sem a substância de interesse). Em seguida, a mistura é novamente agitada e a fase aquosa é coletada para análise assim que um patamar de dessorção é alcançado. Por fim, a concentração da substância remanescente no solo $\left(C_{s}^{\text {des }}\right)$ é plotada em função da concentração da substância dessorvida presente na fase aquosa $\left(C_{a q}^{d e s}\right)$, a fim de que o coeficiente aparente de dessorção $\left(K_{\text {des }}\right)$ seja calculado. Valores de $K_{d,} K_{o c}, K_{F}^{a d s}$ e $K_{d e s}$ para diversos antimicrobianos em solos são apresentados na Tabela 1.

Para que estudos de sorção/dessorção sejam realizados, devem ser feitos testes preliminares com o intuito de que sejam determinadas a razão solo/solução ideal, o tempo de equilíbrio, a quantidade da substância a ser empregada, bem como sua estabilidade durante os ensaios. De acordo com a OECD 106, cinco solos distintos (cobrindo uma faixa ampla de conteúdo de carbono orgânico, porcentagem de argila, textura e $\mathrm{pH}$ ) devem ser utilizados no estudo.

Outros tipos de avaliações, como a lixiviação em coluna, experimentos com lisímetros monolíticos e experimentos em campo, também são empregados para avaliar a mobilidade de contaminantes no solo. No primeiro caso, a OECD 312 orienta que colunas feitas com material inerte (vidro, aço inoxidável, alumínio, teflon ou PVC) sejam preenchidas com solo e posteriormente pré-equilibradas com $\mathrm{CaCl}_{2}$ 0,01 mol L'-1. A substância de interesse deve ser adicionada ao topo da coluna e uma "chuva" é simulada com a adição de $\mathrm{CaCl}_{2}$ $0,01 \mathrm{~mol} \mathrm{~L}^{-1}$ ao sistema. A fase percolada é coletada e a coluna é posteriormente seccionada. As frações de solo e do percolado devem ser analisadas para que seja feita a determinação do composto de interesse. Por fim, as \% recuperadas do contaminante são plotadas em função da profundidade do solo e das frações recolhidas do percolado. Utilizando-se uma substância como referência pode-se ainda comparar o fator relativo de mobilidade (razão entre as distâncias percorridas pela substância de interesse e pelo composto de referência) em diferentes tipos de solos. ${ }^{75}$

Diferentemente da lixiviação em coluna, experimentos com lisímetros monolíticos e estudos em campo são realizados in situ. Por conta disto, o monitoramento dos fluxos de massas de água, bem como a avaliação do transporte e da distribuição dos contaminantes no solo são feitos em condições reais. Lisímetros monolíticos constituem-se em sistemas aterrados e formados por um bloco de solo não desestruturado (com área mínima de $0,5 \mathrm{~m}^{2}$ e profundidade de $1 \mathrm{~m}$ ) que é acondicionado em um invólucro impermeável (feito, por exemplo, de aço inoxidável ou fibra de vidro) e que dispõe de um dispositivo em sua parte inferior para receber e conduzir a água percolada a um reservatório. ${ }^{78}$ Segundo estabelece a OECD 312, a substância de interesse deve ser adicionada ao lisímetro de acordo com sua principal rota de entrada no solo. Desta forma, no caso dos $\mathrm{FV}$ o esterco de animais pode ser utilizado. A água percolada, plantas (que tiverem sido cultivadas sobre o lisímetro) e camadas de solo devem ser analisadas para que a presença e a dispersão do fármaco no sistema sejam estudadas.

A OECD 312 orienta que os solos sejam compactados em colunas com auxílio de colheres, sistemas de pistão ou de vibração. Contudo, o interior das colunas pode ser preenchido por solo na forma de um bloco inteiriço com perfil cilíndrico. Apesar da OECD 312 não fazer nenhuma menção a este tipo de sistema, o mesmo tem sido denominado como lisímetro em algumas situações. ${ }^{79-81}$ A fim de evitar equívocos, tal conjunto será aqui chamado de "coluna de solo não desestruturado". ${ }^{82}$

Por meio de estudos de lixiviação em coluna, Wehrhan et al. ${ }^{83}$ estudaram o transporte da ${ }^{14} \mathrm{C}$-sulfadiazina $\left({ }^{14} \mathrm{C}\right.$-SFZ) no solo e verificaram o ajuste adequado das curvas de eluição do fármaco a um modelo constituído por três sítios de sorção, sendo dois destes reversíveis e um irreversível. Em contrapartida, em estudos empregando colunas de solo não desestruturado, $96 \%$ da ${ }^{14} \mathrm{C}$-SFZ permaneceram sorvidos no solo, após a aplicação do composto à coluna por meio de esterco líquido bovino. ${ }^{81}$ Drillia et al..$^{55}$ utilizaram um modelo matemático para avaliar a mobilidade do SMZ e o efeito provocado pela "chuva" à coluna de solo. O coeficiente de transferência de massa $(k)$ calculado 
para o fármaco foi de $6 \mathrm{~cm}^{3} \mathrm{~min}^{-1}$ (quando se utilizou vazão de 1,6 $\mathrm{mL}$ $\min ^{-1}$ para a aplicação do SMZ na coluna) e de $19,5 \mathrm{~cm}^{3} \min ^{-1}$ (para a vazão de 9,5 $\mathrm{mL} \mathrm{min}^{-1}$ ). Rabølle e Spliid ${ }^{63}$ empregaram estudos de adsorção e de lixiviação em coluna para avaliar o comportamento de 4 antimicrobianos em solos argiloso- arenoso, arenoso-argiloso e arenoso. Os valores de $K_{d}$ verificados para os fármacos seguiram a ordem: MZL < olaquindox < TIL < OTC. De acordo com esta tendência, a mobilidade dos compostos aumentou na ordem inversa: os dois primeiros fármacos moveram-se mais rapidamente na coluna, ao passo que os dois últimos não foram detectados no percolado, sendo fortemente sorvidos nos solos.

Diferentemente do que ocorre com os praguicidas, o emprego de lisímetros monolíticos para a avaliação do comportamento de AV em solos é escasso na literatura. Não muito distante desta situação, os estudos em campo são ainda pouco explorados.

Aplicando esterco de suínos ao solo e empregando coletores de água (posicionados em diferentes profundidades), Blackwell et $a l .{ }^{84}$ realizaram estudos em campo para avaliar a dissipação e o transporte de SFP, OTC e TIL em uma área de 6 x 10 m de um campo de trigo. Por conta de sua rápida degradação no esterco, a TIL não foi encontrada nas amostras de água e de solo. A SFP foi concentrada em uma camada de $30 \mathrm{~cm}$ de solo e detectada em profundidades de até $80 \mathrm{~cm}$. Entretanto, em decorrência de seu alto coeficiente de sorção, a OTC não foi detectada nas amostras de água, sendo concentrada em uma camada de solo com apenas $10 \mathrm{~cm}$ de espessura. Estudos em coluna de solo não desestruturado corroboram com estes últimos resultados. A OTC não foi coletada nas frações do percolado, concentrando-se no solo em profundidades entre 5 e $20 \mathrm{~cm} \cdot{ }^{79,80,85}$ Em estudos de campo Kreuzig e Höltge ${ }^{86}$ verificaram a maior lixiviação de SF em camadas superficiais de áreas de pastagem, já que, neste caso, a compactação do solo dificultou a percolação do fármaco para camadas mais profundas.

\section{DEGRADAÇÃO DE ANTIMICROBIANOS VETERINÁRIOS EM SOLOS E ESTERCOS}

A degradação de antimicrobianos é iniciada no organismo dos animais, via processos metabólicos, que são compostos principalmente por duas fases: reações de funcionalização de fase I, onde ocorrem oxidação, redução e hidrólise de grupos funcionais e reações biossintéticas de fase II, onde ocorrem reações de conjugação. ${ }^{21}$

Entretanto, já que reações de conjugação são reversíveis, é possível que compostos conjugados sejam novamente metabolizados e transformados no antimicrobiano original. ${ }^{21,87}$ Este é o caso da glucuronida de sulfametazina N-4-acetilada que é convertida em SMT em esterco líquido. Após ser administrada, a SMT sofre conjugação com açúcares no fígado que a torna inativa. Contudo, após sua excreção, micróbios degradam os açúcares e convertem o metabólito em sua forma bioativa. ${ }^{88}$

Uma vez excretados, a capacidade de dissipação dos AV dependerá de suas propriedades físico-químicas, além das condições ambientais como tipo de solo, temperatura e pH..$^{2,3}$ Cabe destacar que o esterco pode reduzir a taxa de degradação destes poluentes à medida que este serve como uma proteção à luz e, consequentemente, às reações de fotodegradação de alguns antimicrobianos. ${ }^{4,21}$ Desta forma, AV podem persistir no interior de pilhas de esterco devido à decomposição microbiana baixa ou mínima nesta área. ${ }^{89}$ Assim, compostos susceptíveis às reações de fotodegradação como FQ, TET e SF podem ser gradativamente acumulados e posteriormente espalhados pelo solo., ${ }^{4,21}$ Tal comportamento foi verificado em estudos de determinação da OCT em pilhas de esterco de bezerros. A concentração de OTC, determinada nas camadas intermediárias e profundas dos excrementos, foi consideravelmente maior que a encontrada nas camadas superficiais, como consequência da diminuição da capacidade de degradação do fármaco. ${ }^{90}$

Mesmo após a degradação dos AV no ambiente, a eliminação de sua atividade antibacteriana pode não ser completa, uma vez que alguns produtos de degradação apresentam toxicidade similar ou maior que o composto original. ${ }^{2}$ Halling-Sørensen et al.$^{87}$ avaliaram a toxicidade de TET e seus principais produtos de degradação a bactérias isoladas do solo e do lodo de esgoto. Com exceção das Pseudomonas, os micro-organismos avaliados apresentaram sensibilidade à maioria dos compostos parentes. Estruturas como o hidrocloreto de 5a,6-anidrotetraciclina (ATC), $\alpha$ e $\beta$-apo-oxitetraciclina tiveram a mesma potência do fármaco original. ATC, hidrocloreto de 4-epi-anidrotetraciclina, hidrocloreto de 5a,6-anidroclortetraciclina e hidrocloreto de 4-epi-clortetraciclina (ECTC) apresentaram alta toxicidade até mesmo às bactérias que carregavam genes resistentes às TET. Estudos realizados por Kusari et $a l .{ }^{91}$ mostraram que a difloxacina, sarafloxacina e seus subprodutos de fotólise em meio aquoso apresentaram atividade antibacteriana efetiva contra a bactéria Gram negativa Klebsiella pneumoniae e à bactéria Gram positiva Staphylococcus aureus.

Um modo de reduzir os efeitos ecológicos adversos, provocados pela dispersão de estrume contaminado no solo, pode ser a compostagem deste material. Este processo resulta na morte de organismos patogênicos, na diminuição da concentração do fármaco e na geração de um produto com pouco odor, que pode ser armazenado ou espalhado pelo campo. ${ }^{5,92}$ Por meio da compostagem foi possível degradar a CTC, em mais de $90 \%$ de sua concentração inicial, em amostras de esterco de frangos. ${ }^{5}$ Arikan et al..$^{93}$ verificaram a degradação de $95 \%$ da concentração inicial de OTC durante a compostagem de fezes de bezerros. Apesar deste estudo não avaliar os produtos de degradação, gerados através da decomposição da OTC, foi averiguado que houve um aumento na concentração de bactérias heterotróficas durante a compostagem. Em contrapartida, o número de bactérias resistentes à OTC sofreu decréscimo.

Durante a compostagem, as temperaturas no interior de pilhas de esterco podem atingir $45^{\circ} \mathrm{C}$ em decorrência da respiração microbiana. ${ }^{89}$ Entretanto, por meio da adição de palha às pilhas de estrume de bezerros foi possível atingir temperaturas de até $70^{\circ} \mathrm{C}$, o que juntamente com a aeração dos excrementos acarretou em degradação de mais de $99 \%$ da CTC e ECTC ${ }^{89}$ Diferentemente deste resultado, o processo de digestão anaeróbica da OTC resultou em somente $59 \%$ de degradação do fármaco. ${ }^{94}$

Kühne et al. ${ }^{95}$ estudaram a degradação da TC em estrume líquido de suínos e confirmaram que o tempo para a redução da concentração do composto em $50 \%\left(D_{T 50}\right)$ reduziu de 9 para 4,5 dias quando os excrementos foram continuamente misturados e aerados. Wang e Yates ${ }^{96}$ verificaram que o aumento na porcentagem da água de saturação do esterco (de 39 para 64\%) reduziu o $D_{T 50}$ da OTC de 9,3 para 7,8 dias sob condições aeróbicas. Outras taxas de degradação de inúmeros antimicrobianos, em solos e estercos, podem ser consultadas em Thiele-Bruhn ${ }^{21}$ e Sarmah et al.. ${ }^{3}$

Além das condições aeróbicas, acréscimos na temperatura podem favorecer o aumento da taxa de degradação de AV bem como da descontaminação dos estercos. ${ }^{3}$ Nicholson et al.$^{97}$ verificaram que a Escherichia coli, a Salmonella, o Campylobacter jejuni e a Listeria monocytogenes sobreviveram em estercos armazenados por mais de 3 meses. Em contrapartida, com o aquecimento das pilhas de estrume (a temperaturas acima de $55^{\circ} \mathrm{C}$ ) este período foi reduzido para menos de 1 mês.

\section{Determinação da cinética de degradação de fármacos veterinários em solos}

A determinação da cinética de degradação de FV em solos foi 
estabelecida pela EMEA, devendo ser realizada na fase I e obedecer ao guia OECD 307.

De acordo com a OECD 307, amostras de solo fortificadas em diferentes níveis com o fármaco de interesse devem ser incubadas sob proteção da luz e à temperatura constante, em frascos do tipo biômetro ou em sistemas de fluxo. Após intervalos apropriados de tempo, amostras de solo devem ser coletadas, extraídas e analisadas para a determinação da concentração do FV. Em seguida, a concentração do FV remanescente no solo é plotada em função do tempo. Por fim, um modelo cinético é ajustado aos dados para que seja realizado o cálculo do $D T_{50}$ do composto. ${ }^{98}$ Modelos de primeira ordem, primeira ordem ajustado, bi-exponencial e bifásico foram empregados neste caso. ${ }^{5,90,96,99-101}$

Os estudos de determinação da cinética de biodegradação de FV devem ser conduzidos sob condições aeróbicas e anaeróbicas. No primeiro caso, os frascos devem ser inicialmente pesados para que a perda de umidade seja compensada com adição de água. Os sistemas de fluxo precisam ser purgados ou continuamente ventilados com ar úmido. No segundo caso, os solos devem ser saturados com água e o sistema lacrado após ser purgado com gás inerte. ${ }^{98}$ De acordo com a OECD 307, os solos empregados nestes estudos devem ser coletados em áreas cultiváveis que não receberam nenhum tratamento nos últimos 5 anos. As amostras devem ser caracterizadas quanto ao $\mathrm{pH}$, à porcentagem de matéria orgânica, à distribuição do tamanho das partículas e à umidade. A taxa de dissipação do fármaco deve ser avaliada em, no mínimo, três tipos de solos, cobrindo uma ampla faixa de $\mathrm{pH} .{ }^{98}$

Uma vez que a persistência de antimicrobianos não está condicionada apenas às características físico-químicas dos fármacos, mas também aos fatores ambientais, o $D T_{50}$ destes compostos em solos pode ser superestimado, já que as condições ambientais não são perfeitamente reproduzidas em laboratório. ${ }^{3}$ Em estudos realizados in vitro, empregando três solos distintos, a OTC apresentou $D T_{50}$ de 30 a 46 dias sob condições aeróbicas e de 43 a 62 dias sob condições anaeróbicas. ${ }^{102}$ Entretanto, em estudos realizados in vivo por Blackwell et al. ${ }^{84}$ e Aga et al. ${ }^{20}$ o $D T_{50}$ encontrado para a OTC foi de 22 a 23 dias.

\section{CONCLUSÃO}

A contaminação do meio ambiente provocada pela presença de AV é uma realidade. Entretanto, diferente do que ocorre com os agrotóxicos e outros poluentes, o comportamento de fármacos no meio ambiente ainda não tem sido extensivamente estudado. Sendo assim, existe uma carência de dados quantitativos que estimem a extensão desta contaminação, de estudos sobre a mobilidade destes fármacos, de métodos adequados para a determinação dos mesmos no solo e dos impactos ambientais provocados por sua presença no ambiente. ${ }^{4,38,103,104}$

$\mathrm{O}$ desconhecimento das consequências que podem ocorrer em longo prazo pela dispersão de bactérias resistentes fez com que países desenvolvidos adotassem medidas preventivas, a fim de evitar que estes micro-organismos fossem disseminados por meio do consumo de produtos de origem animal. Atualmente, os Estados Unidos, União Europeia e Japão dispõem de guias que regulamentam a avaliação de novos produtos veterinários no que diz respeito aos impactos ambientais e aos efeitos microbiológicos que podem ser provocados pelas bactérias de interesse à saúde humana. Outra ação positiva, tomada pela VICH, foi o estabelecimento do limite máximo aceitável para a presença de AV no solo.

Atualmente, o Brasil conta com o Programa de Análise de Resíduos de Fármacos Veterinários em Alimentos de Origem Animal (PAMVet). Contudo, não existe nenhum programa responsável pelo acompanhamento destes fármacos no ambiente. Sendo assim, há necessidade urgente de avaliações do comportamento de AV em solos brasileiros e da disponibilização de métodos analíticos sensíveis e adequados para o monitoramento dos mesmos.

\section{AGRADECIMENTOS}

L. A. Pereira agradece à Fundação de Amparo à Pesquisa do Estado de São Paulo (FAPESP) pela concessão de apoio financeiro para a realização deste trabalho.

\section{LISTA DE ABREVIATURAS}

${ }^{14} \mathrm{C}$-SFZ: ${ }^{14} \mathrm{C}$-sulfadiazina

ATC: hidrocloreto de 5a, 6-anidrotetraciclina

$\mathrm{AV}$ : antimicrobianos veterinários

BCF: fatores de bioconcentração (bioconcentration factors)

$C_{s}^{a d s}$ : concentração da substância adsorvida no solo

$C_{a q}^{a d s}$ : concentração em equilíbrio na fase aquosa

$C_{s, m a x}^{a d s}$ : capacidade máxima de sorção do sorbente

$C_{s}^{d e s}$ : concentração da substância remanescente no solo

$C_{a q}^{d e s}$ : concentração da substância dessorvida presente na fase aquosa

CIP: ciprofloxacina

CTC: clortetraciclina

$D_{T 50}$ : tempo para a redução da concentração do composto em $50 \%$

DC: doxiciclina

ECTC: hidrocloreto de 4-epi-clortetraciclina

EMEA: Agência Europeia para a Avaliação de Produtos Medicinais

(European Agency for the Evaluation of Medical Products)

ENR: enrofloxacina

FDA: Administração de Alimentos e Medicamentos dos Estados Unidos (Food and Drug Administration)

FLO: florfenicol

FQ: fluoroquinolonas

$\mathrm{FV}$ : fármacos veterinários

JECFA: Comitê de Peritos em Aditivos Alimentares (Joint Expert Committee on Food Additives)

$\mathrm{K}_{\mathrm{ow}}$ : coeficiente de partição octanol-água

$K_{d}$ : coeficiente de distribuição de adsorção

$K_{o c}$ : coeficiente de adsorção normalizado pelo carbono orgânico

$K_{F}^{a d s}$ : coeficiente de adsorção de Freundlich

$K_{L}$ : coeficiente de sorção de Langmuir

$K_{d e s}:$ coeficiente aparente de dessorção

MO: matéria orgânica

MRL: limites máximos de resíduos (maximum residue limits)

MZL: metronidazol

NOEC: concentração de efeito não observado (no-observed effect concentraction)

NOR: norfloxacina

OTC: oxitetraciclina

PAMVet: Programa de Análise de Resíduos de Fármacos Veterinários em Alimentos de Origem Animal

PEC: concentração ambiental previsível (predicted environmental concentration)

PNEC: concentração previsível sem efeito (predicted no effect concentration)

QSAR: relação quantitativa estrutura atividade (quantitative structure activity relationship)

RQ: quociente de risco (risk quocient)

SDX: sulfadimetoxina

SH: substâncias húmicas

SF: sulfonamidas

SFP: sulfacloropiridazina

SFZ: sulfadiazina 
SMT: sulfametazina

SMZ: sulfametoxazol

TC: tetraciclina

TET: tetraciclinas

TIL: tilosina

TMP: trimetoprima

VICH: Conferência Internacional de Harmonização dos Medicamentos Veterinários (Veterinary International Committee on Harmonization)

\section{REFERÊNCIAS}

1. Díaz-Cruz, M. S.; de Alda, J. L.; Barceló, D.; Trends Anal. Chem. 2003, 22,340 .

2. Boxall, A. B. A.; Kolpin, D. W.; Halling-Sørensen, B. H.; Tolls, J.; Environ. Sci. Technol. 2003, 287A.

3. Sarmah, A. K.; Meyer, M. T.; Boxall, A. B. A.; Chemosphere 2006, 65, 725 .

4. Kemper, N.; Ecological Indicators 2008, 8, 1 .

5. Bao, Y.; Zhou, Q.; Guan, L; Wang, Y.; Waste Management 2009, 29, 1416.

6. EMEA; Note for guidance: environmental risk assessment for veterinary medical products other than GMO-containing and immunological products, Committee for Veterinary and Medical Products: London, 1997.

7. European Commission (EC); Regulation (EC) No 1831/2003 of the European Parliament and of the Council of 22 September 2003 on Additives for Use in Animal Nutrition.

8. Díaz-Cruz, M. S.; Barceló, D.; Trends Anal. Chem. 2007, 26, 637.

9. Kolls, S. A. E.; Moltmann, J. F.; Knacker, T.; Regulatory Toxicology and Pharmacology 2008, 50, 59.

10. h t t p : / / w w w. if a h e urope.org / Com mon T P. aspx ?SubMenuId=37\&MenuId=3, acessada em Novembro 2010.

11. http://www.sindan.org.br/sd/sindan/index.html, acessada em Novembro 2010.

12. Haller, M. Y.; Müller, S. R.; McArdell, C. S.; Alder, A. C.; Suter, M. J. F.; J. Chromatogr., A 2002, 952, 111.

13. Jjemba, P. K.; Agriculture, Ecosystems and Environment 2002, 93, 267.

14. Yu, T. H.; Lin, A. Y.C.; Lateef, S. K.; Lin, C. F.; Yang, P. Y.; Chemosphere 2009, 77, 175.

15. Beause, J.; Trends Anal. Chem. 2004, 23, 753.

16. Dolliver, H.; Kumar, K.; Gupta, S.; J. Environ. Qual. 2007, 36, 1224.

17. Christian, T.; Schneider, R. J.; Farber, H. A.; Skutlarek, D.; Meyer, M. T.; Goldbach, H. E.; Acta Hydrochimica et Hydrobiologica 2003, 31, 36.

18. Hamscher, G.; Sczesny, S.; Höper, H.; Nau, H.; Anal. Chem. 2002, 74, 1509.

19. Stoob, K.; Singer, H. P.; Mueller, S. R.; Schwarzenbach, R. P.; Stamm, C. H.; Environ. Sci. Technol. 2007, 41, 7349.

20. Aga, D. S.; O'Connor, S.; Ensley, S.; Payero, J. O.; Snow, D.; Tarkalson, D.; J. Agric. Food Chem. 2005, 53, 7165.

21. Thiele-Bruhn, S.; J. Plant Nutr. Soil Sci. 2003, 166, 145.

22. Chander, Y.; Kumar, K.; Goyal, S. M.; Gupta, S. C.; J. Environ. Qual. 2005, 34, 1952.

23. Zhou, X.; Chen, C.; Yue, L.; Sun, Y.; Ding, H.; Liu, Y.; Environ. Toxicol. Pharmacol. 2008, 26, 272.

24. Kinney, C. A.; Furlong, E. T.; Kolpin, D. W.; Burkhardt, M. R.; Zaugg, S. D.; Werner, S. L.; Bossio, J. P.; Benotti, M. J.; Environ. Sci. Technol. 2008, 42, 1863.

25. Boxall, A. B. A.; Johnson, P.; Smith, E. J.; Sinclair, C. J.; Stutt, E.; Levy, L. S.; J. Agric. Food Chem. 2006, 54, 2288.

26. Kumar, K.; Gupta, S. C.; Baidoo, S. K.; Chander, Y.; Rosen, C. J.; J. Environ. Qual. 2005, 34, 2082.
27. Migliore, L.; Civitareale, C.; Brambilla, G.; Cozzolino, S; Casoria, P.; Gaudio, L.; Agriculture, Ecosystems and Environment 1997, 65, 163.

28. Migliore, L.; Civitareale, C.; Cozzolino, S.; Casoria, P.; Brambilla, G.; Gaudio, L.; Chemosphere 1998, 37, 2957.

29. Jjemba, P. K.; Chemosphere 2002, 46, 1019.

30. Sengel $\varnothing v$, G.; Agers $\varnothing$, Y.; Halling-Sørensen, B.; Baloda, S. B.; Andersen, J. S.; Jensen, L. B.; Environment International 2003, 28, 587.

31. VICH; Guidance on pre-approval information for registration of new veterinary medical products for food-producing animals with respect to antimicrobial resistance, 2004; http://www.fda.gov/downloads/AnimalVeterinary/GuidanceComplianceEnforcement/GuidanceforIndustry/ ucm052524.pdf, acessada em Novembro 2010.

32. FDA; Guidance for Industry $n{ }^{\circ} 152$. Evaluating the safety of antimicrobial new drugs with regard to their microbiological effects on bacteria of human health concern, 2003; http://www.fda.gov/ downloads/AnimalVeterinary/GuidanceComplianceEnforcement/ GuidanceforIndustry/UCM052519.pdf, acessada em Novembro 2010.

33. Morris, A. K.; Masterton, R. G.; J. Antimicrob. Chemother. 2002, 49, 7.

34. Jensen, L. B.; Baloda, S.; Boye, M.; Aarestrup, F. M.; Environment International 2001, 26, 581.

35. Onan, L. J.; LaPara, T. M.; Fed. Eur. Microbiol. Soc. 2003, 220, 15.

36. Venglovsky, J.; Sasakova, N.; Placha, I.; Bioresour. Technol. 2009, 100, 5386.

37. Picó, Y.; Andreu, V.; Anal. Bioanal. Chem. 2007, 387, 1287.

38. O' Connor, S.; Aga, D. S.; Trends Anal. Chem. 2007, 26, 456.

39. Andreu, V.; Vazquez-Roig, P.; Blasco, C.; Pico, Y.; Anal. Bioanal. Chem. 2009, 394, 1329.

40. Watkinson, A. J.; Murby, E. J.; Kolpin, D. W.; Costanzo, S. D.; Sci. Total Environ. 2009, 407, 2711.

41. Kolpin, D. W; Skopec, M.; Meyer, M. T.; Furlong, E. T.; Zaugg, S. D.; Sci. Total Environ. 2004, 328, 119.

42. Lindsey, M. E.; Meyer, M; Thurman, E. M.; Anal. Chem. 2001, 73, 4640.

43. Yang, S.; Carlson, K.; Water Res. 2003, 37, 4645.

44. Yang, S.; Carlson, K.; Water Res. 2004, 38, 3155.

45. Castiglioni, S.; Fanelli, R.; Calamari, D.; Bagnati, R.; Zuccato E.; Regulatory Toxicology and Pharmacology 2004, 39, 25.

46. Ashton, D.; Hilton, M.; Thomas, K. V.; Sci. Total Environ. 2004, 333, 167.

47. Thomas, K. V.; Hilton, M. J.; Mar. Pollut. Bull. 2004, 49, 436.

48. Hilton, M. J.; Thomas, K. V.; J. Chromatogr., A 2003, 1015, 129.

49. Zuccato, E.; Calamari, D.; Natangelo, M.; Fanelli, R.; Research Letters 2000, 355, 1789.

50. WHO, Joint FAO/WHO Expert Committee on Food Additives; Evaluation of certain veterinary drug residues in food: sixty-sixth report of the Joint FAO/WHO Expert Committee on Food Additives, WHO technical report series, no. 939, 2006.

51. VICH; Environmental impact assessments (EIAs) for veterinary medical products (VMPS): Phase I, 2000; http://www.vichsec.org/pdf/2000/ G106_st7.pdf, acessada em Novembro 2010.

52. VICH; Guideline on environmental impact assessment for veterinary medical products - Phase II, 2004; http://www.ema.europa.eu/docs/ en_GB/document_library/Scientific_guideline/2009/10/WC500004393. pdf, acessada em Novembro 2010.

53. EMEA; Guideline on environmental impact assessment for veterinary medical products in support of the VICH guidelines GL6 and GL38, 2008; http://www.ema.europa.eu/docs/en_GB/document_library/Scientific_guideline/2009/10/WC500004386.pdf, acessada em Novembro 2010.

54. Chesworth, W.; Encyclopedia of Soil Chemistry, Springer: Dordrecht, 2008.

55. Drillia, P.; Stamatelatou, K.; Lyberatos, G.; Chemosphere 2005, 60, 1034. 
56. Sassman, S. A.; Lee, L. S.; Environ. Sci. Technol. 2005, 39, 7452.

57. Pils, J. R. V.; Laird, D. A.; Environ. Sci. Technol. 2007, 41, 1928.

58. Boxall, A. B. A.; Blackwell, P.; Cavallo, R.; Kay, P.; Tolls, J.; Toxicol. Lett. 2002, 131, 19

59. Yeager, R. L.; Halley, B. A.; J. Agric. Food Chem. 1990, 38, 883.

60. Williams, C. F.; Adamsen, F. J.; J. Environ. Qual. 2006, 35, 1779.

61. Vasudevan, D.; Bruland, G. L.; Torrance, B. S.; Upchurch, V. G.; Mackay, A. A.; Geoderma 2009, 151, 68.

62. Nowara, A.; Burhenne, J.; Spiteller, M.; J. Agric. Food Chem. 1997, 45, 1459.

63. Rabølle, M.; Spliid, N. H.; Chemosphere 2000, 40, 715.

64. Jie, Z.; Zhaojun, L.; Gaofei, G.; Wanchun, S.; Yongchao, L.; Laosheng, W.; J. Environ. Sci. 2009, 21, 632.

65. Kulshrestha, P.; Giese, R. F.; Aga, D. S.; Environ. Sci. Technol. 2004, 38, 4097.

66. Figueroa, R. A.; Mackay, A. A.; Environ. Sci. Technol. 2005, 39, 6664

67. Accinelli, C.; Koskinen, W. C.; Becker, J. M.; Sadowsky, M. J.; J. Agric. Food Chem. 2007, 55, 2677.

68. Thiele-Bruhn, S.; Seibicke, T.; Schulten, H. R.; Leinweber, P.; J. Environ. Qual. 2004, 33, 1331.

69. Thiele, S.; J. Plant Nutr. Soil Sci. 2000, 163, 589.

70. Tolls, J.; Environ. Sci. Technol. 2001, 35, 3397.

71. Andreu, V.; Vazquez-Roig, P.; Blasco, C.; Picó, Y.; Anal. Bioanal. Chem. 2009, 394, 1329.

72. García-Galán, M. J.; Díaz-Cruz, M. S.; Barceló, D.; Trends Anal. Chem. 2009, 28, 804.

73. Figueroa, R. A.; Leonard, A.; Mackay, A. A.; Environ. Sci. Technol. 2004, 38, 476.

74. OECD; OECD Guidelines for the Testing of Chemicals. Section 1: Physical-chemical properties. Test $n^{\circ}$ 106: Adsorption - desorption using a batch equilibrium method, Organization for the Economic Cooperation and Development, 2000.

75. OECD; OECD Guidelines for the Testing of Chemicals. Section 3: Degradation and Accumulation. Test $n^{\circ}$ 312: Leaching in soil columns, Organization for the Economic Cooperation and Development, 2004.

76. Carmosini, N.; Lee, L. S.; Chemosphere 2009, 77, 813.

77. Travis, C. C.; Etnier, E. L.; J. Environ. Qual. 1981, 10, 8.

78. OECD; Series on Testing and Assessment $n^{\circ} 22$. Guidance document for the performance of out-door monolith lysimeter studies, Organization for the Economic Cooperation and Development, 2000.

79. Kay, P.; Blackwell, P. A.; Boxall, A. B. A.; Environ. Pollut. 2005, 134, 333.
80. Blackwell, P. A.; Kay, P.; Ashauer, R.; Boxall, A. B. A.; Chemosphere 2009, 75, 13.

81. Kreuzig, R.; Höltge, S.; Brunotte, J; Berenzen, N.; Wogram, J.; Schulz, R.; Environ. Toxicol. Chem. 2005, 24, 777.

82. Ribeiro, M. L.; Lourencetti, C.; Pereira, S. Y.; de Marchi, M. R. R.; Quim. Nova 2007, 30, 688 .

83. Wehrhan, A.; Kasteel, R.; Simunek, J.; Groeneweg, J.; Vereecken, H.; J. Contam. Hydrol.. 2007, 89, 107.

84. Blackwell, P. A.; Kay, P.; Boxall, A. B. A.; Chemosphere 2007, 67, 292.

85. Kay, P.; Blackwell, P. A.; Boxall, A. B. A.; Chemosphere 2005, 60, 497.

86. Kreuzig, R.; Höltge, S.; Environ. Toxicol. Chem. 2005, 24, 771.

87. Halling-Sørensen, B.; Sengeløv, G.; Tjørnelund, J.; Arch. Environ. Contam. Toxicol. 2002, 42, 263.

88. Renner, R.; Environ. Sci. Technol. 2002, 36, 194 A.

89. Arikan, O.; Mulbry, W.; Ingram, D.; Millner, P.; Bioresour. Technol. 2009, 100, 4447.

90. de Liguoro, M.; Cibin, V.; Capolongo, F.; Halling-Sørensen, B.; Montesissa, C.; Chemosphere 2003, 52, 203.

91. Kusari, S.; Prabhakaran, D.; Lamshöft, M.; Spiteller, M.; Environ. Pollut. 2009, 157, 2722.

92. Arikan, O. A.; Mulbry, W.; Rice, C.; J. Hazard. Mater. 2009, 164, 483.

93. Arikan, O. A.; Sikora, L. J.; Mulbry, W.; Khan, S. U.; Foster, G. D.; Bioresour. Technol. 2007, 98, 169.

94. Arikan, O. A.; Sikora, L. J.; Mulbry, W.; Khan, S. U.; Rice, C.; Foster, G. D.; Process Biochem. 2006, 41, 1637.

95. Kühne, M.; Ihnen, D.; Möller, G.; Agthe, O.; J. Veterinary Medicine A 2000, 47, 379 .

96. Wang, Q.; Yates, S. R.; J. Agric. Food Chem. 2008, 56, 1683.

97. Nicholson, F. A.; Groves, S. J.; Chambers, B. J.; Bioresour. Technol. 2005, 96, 135.

98. OECD; OECD Guidelines for the Testing of Chemicals. Test $n^{o} 307$ : Aerobic and Anaerobic transformation in soil, Organization for the Economic Cooperation and Development, 2002.

99. Søeborg, T.; Ingerslev, F.; Halling-Sørensen, B.; Chemosphere 2004, 57,1515

100. Lai, H. T.; Lin, J. J.; Chemosphere 2009, 75, 462.

101. Schlüsener, M. P.; Bester, K.; Environ. Pollut. 2006, 143, 565.

102. Yang, J. F.; Ying, G. G.; Zhou, L. J.; Liu, S.; Zhao, J. L.; Environ. Pollut. 2009, 157, 2704.

103. Schmitt, H.; Stoob, K.; Hamscher, G.; Smit, E.; Seinen, W.; Microbial Ecology 2006, 51, 267.

104. Kim, S. C.; Carlson, K.; Anal. Bioanal. Chem. 2007, 387, 1301. 